\title{
Mantis shrimp larvae from the inshore waters of Visakhapatnam, India
}

\author{
S. VEENA ${ }^{1}$ AND P. KALADHARAN ${ }^{2}$ \\ ${ }^{1}$ Visakhapatnam Regional Centre of CMFRI, Pandurangapuram, Visakhapatnam 530003, India, ${ }^{2}$ Calicut Research Centre of CMFRI, \\ Westhill PO, Kozhicode 673005, India
}

\begin{abstract}
Mantis shrimp larvae were collected by a shore seine net operated at Nagamayapalem, Visakhapatnam, India at a depth of 10-12 $\mathrm{m}$ during the early hours of 20 March 2008. Larvae were classified into one group and were identified to a single species of the genus Harpiosquilla. Although mantis shrimp larvae have been found in these waters, there have been no studies that identify them to the species level.
\end{abstract}

Keywords: mantis shrimp larvae, shore seine, Harpiosquilla harpax, Visakhapatnam

Submitted 9 August 2010; accepted 5 November 2010

\section{INTRDDUCTION}

Knowledge of stomatopod larvae, both taxonomically and ecologically, is limited. At least 450 extant species have been described worldwide (Ahyong, 2001) arrayed in 17 families and 7 superfamilies (Ahyong \& Lowry, 2001). Shanbhogue (1975b) reported the presence of 115 species falling under 27 genera and 4 families from the Indian Ocean region. Most species of stopmatopods live in shallow water, species of the superfamily Bathysquilloidea are found on outer shelf habitats, down to $1500 \mathrm{~m}$ (Manning, 1991). Reports by Hof (1998) and Ahyong \& Harling (2000) are the most recent phylogenetic studies of the stomatopods, and Manning (1995) and Ahyong (2001) are the most recent major taxonomic studies.

The late larval stages are transparent and are active predaQuest 3-D, 2001). The major contributions on the study of stomatopod larvae are Milne-Edwards (1837); Brooks (1886, 1892); Hansen (1895); Foxon (1932, 1939); Gurney (1937, 1946); Townsley (1953); Lebour (1954); Serene (1954); Gohar \& Al-Kholy (1957); Manning (1962); Manning \& Provenzano (1963); Ingle \& Della Croce (1967); Michel \& Wing (1972); Alikunhi (1975); Provenzano \& Manning (1978); Morgan \& Provenzano (1979); Greenwood \& Williams (1984); Cronin et al. (1995) and Moazzam \& Moazzam (2006).

From the Indian Ocean region stomatopod larvae have been studied by Lanchester (1903); Tattersall (1906) and Borradaile (1907). Our knowledge of stomatopod larvae from the seas around India comprises 86 species which have been studied by Lele (1937); Nair (1941); Alikunhi \& Gopala Aiyar (1942, 1943); Alikunhi (1944a, b, 1950, 1952, 1959, 1965); Shanbhogue (1975a, b, 1978) and Bano \& Kazmi (2007). The present study reports the stomatopod larvae collected from the shore of Visakhapatnam in India tors in the plankton community (Jutte et al., 1998; Image

and identification to the species level for the first time from the Indian east coast.

\section{MATERIALS ANDMETHDDS}

Specimens of the mantis shrimp larvae were collected by a shore seine net of $20-25 \mathrm{~m}$ span operated off Nagamayapalem, Visakhapatnam inshore area $\left(17^{\circ} 50^{\prime} 46.31^{\prime \prime} \mathrm{N}\right.$ $\left.83^{\circ} 24^{\prime} 44.25^{\prime \prime} \mathrm{E}\right)$; at a depth of $10-12 \mathrm{~m}$ on 20 March 2008. The net operation was done during the early hours of the day for a period of two hours. The catch comprised mainly juveniles of leiognathids, lesser sardines (Sardinella fimbriata), lizard fish (Saurida tumbil), and cephalopods of the Sepiidae, besides the mantis shrimp larval specimens being reported. A few octopus and gastropods also were seen in the catch. The net also dragged in about $500 \mathrm{~g}$ of plastic materials and some floating weeds.

The stomatopod larvae were seen entangled in the net and were carefully sorted. They were preserved in separate pet containers with $70 \%(\mathrm{v} / \mathrm{v})$ ethanol. Identification of the specimens was done using the reports by Brooks (1886); Nair (1941); Alikunhi \& Gopala Aiyar (1942, 1943); Alikunhi (1944a, b, 1950, 1952, 1959, 1965); Shanbhogue (1975a); Ahyong (2002) and Ahyong et al. (2008). For photographic documentation and detailed study, a Fuji camera A850 fitted on an Olympus binocular microscope was used.

RESULTS

Six specimens of mantis shrimp larvae were examined.

\section{SYSTEMATICS}

Corresponding author:

S. Veena

Email: veenashettigar@yahoo.co.in
Order STOMATOPODA Latreille, 1817

Superfamily SQUILLOIDEA Latreille, 1802

Family SQUILLIDAE Latreille, 1802 
Genus Harpiosquilla Holthuis, 1964

Harpiosquilla harpax (de Haan, 1844)

(Figure 1)

\section{MATERIAL EXAMINED}

Late pelagic larval Stage 5(Nagamayapalem, Visakhapatnam inshore area, $17^{\circ} 50^{\prime} 46.31^{\prime \prime} \mathrm{N} 83^{\circ} 24^{\prime} 44.25^{\prime \prime} \mathrm{E}$; depth 10 $12 \mathrm{~m})$, coll. S. Veena, 20 March 2008.

The specimens are $29-38 \mathrm{~mm}$ in length from the tip of the rostral spine to the posterior margin of the telson. Larvae are classified into one group and identified as a single species of the genus Harpiosquilla. Six pelagic stages have been identified previously (Brooks, 1886), but the stage in our findings comprised only late pelagic larval Stage 5. The adult of Harpiosquilla harpax is a common species available in these waters (Shanbhogue, 1969) and the larvae examined resemble those of Harpiosquilla harpax reported by Shanbhogue (1975a, b), but further study by culture of the larvae would help to confirm the identification, and hence the search for live specimens continues. The larvae are known to occur in these waters during the months of March-May. The larvae were transparent when they were collected, but on preservation they turned yellowish in colour.

\section{DESCRIPTION OF LARVAE EXAMINED}

The body is narrow and elongated, exposed hind body is about half the total length as measured from tip of the long slender rostrum to posterior margin of the telson (Figure 1). The raptorial claw of the second thoracic appendage is narrow and greatly elongated; the dactylus is only about half as long as the propodus (Figure 4). The telson has six large marginal carinae, with minute denticles between the submedian carinae, and also between the submedian and intermediate carinae (Figure 5). The anterolateral angle of the carapace

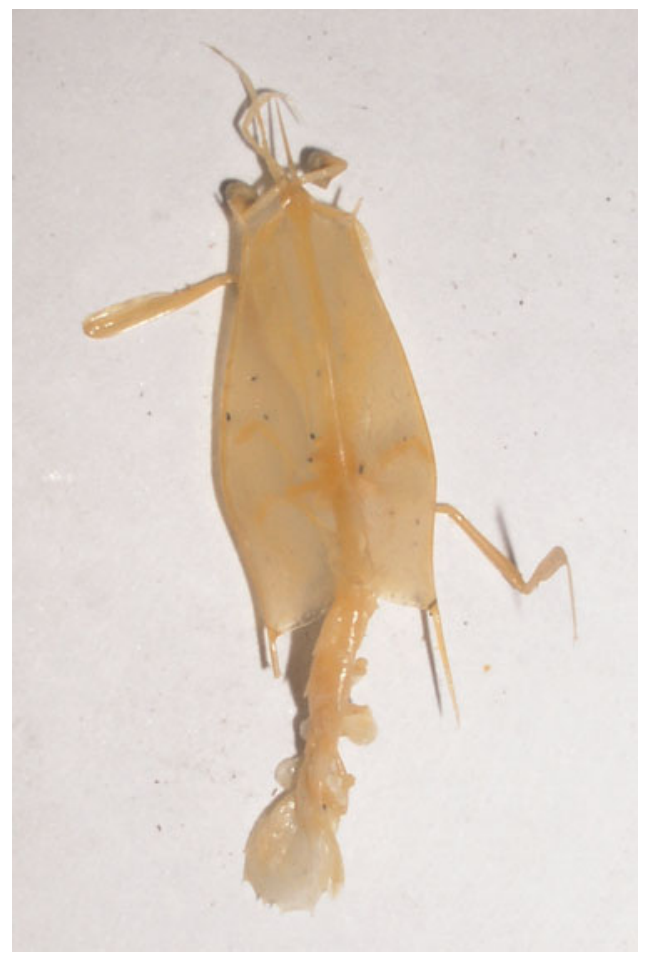

Fig. 1. Harpiosquilla harpax, dorsal view.

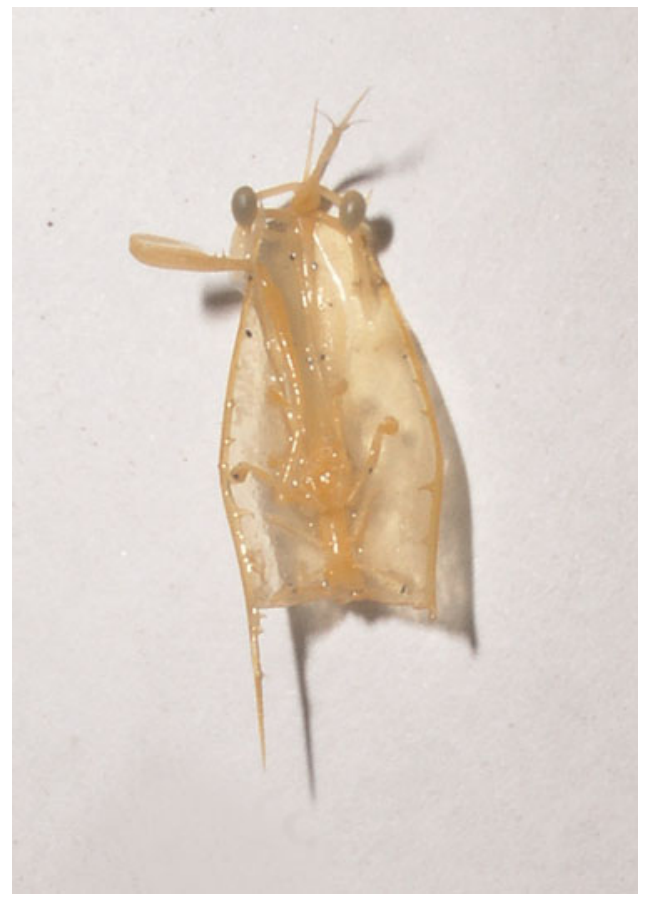

Fig. 2. Carapace with spines.

has nine small spines on both sides. There are small dorsomedian spines on the posterior edge of the carapace which exposes the last three thoracic somites and another slightly longer spine on the median anterior side of the carapace (Figure 2). The eyes are pear-shaped and the stalks very long (Figure 3). The 5th, 6th, 7 th and 8 th thoracic somites are shortened, and their appendages are bud-like. The abdominal somites are also short and appendages are represented by a minute bilobed bud (Figure 6). This larva has all the appendages of the adult, either functional or represented by buds, and all the somites of the hind body. The rostrum is very short and pointed. The width of the carapace is about half its length. The carapace with the rostrum makes

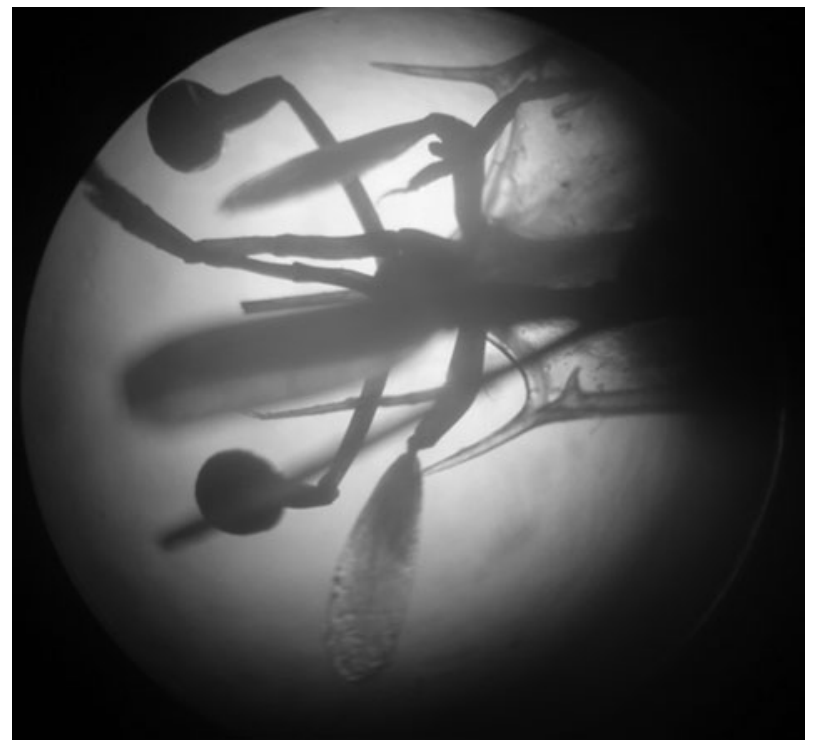

Fig. 3. Stalked eyes. 


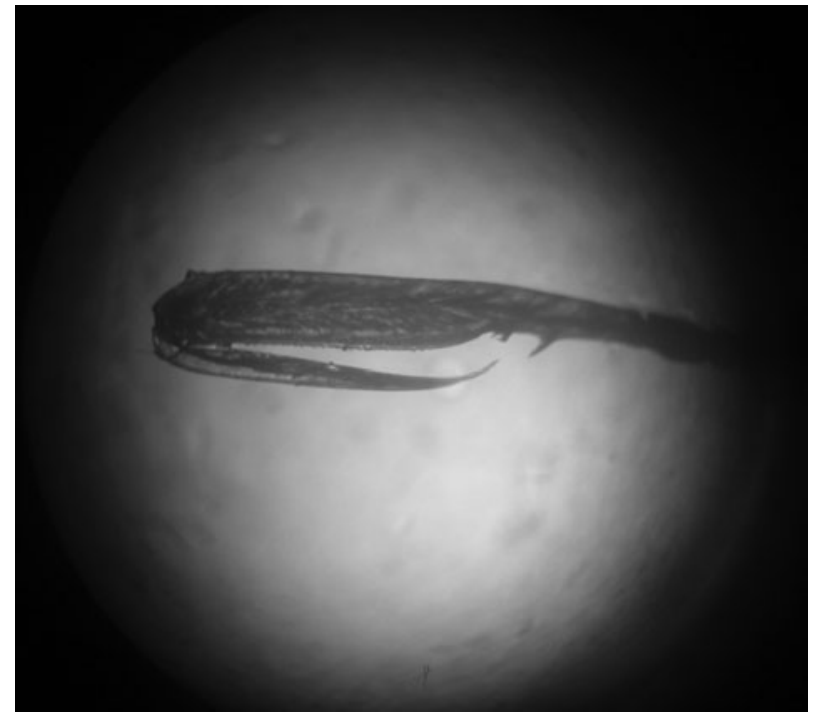

Fig. 4. Claw of appendage.

up almost exactly half of the total length. Total length is $29 \mathrm{~mm}$, median length of the carapace $14 \mathrm{~mm}$, anterior width of the carapace $4 \mathrm{~mm}$, maximum width of the carapace $7 \mathrm{~mm}$, length of the rostrum $3.8 \mathrm{~mm}$, width of the eye $1 \mathrm{~mm}$, median length of the telson $3.2 \mathrm{~mm}$, and width of telson $3 \mathrm{~mm}$.

\section{DISCUSSIDN}

Considering the magnitude of the quantities of stomatopods landed along the entire coastline of India by the indigenous craft and the mechanized trawlers the stomatopods are an important group of crustaceans, although they are not fully utilized in the country (Shanbhogue, 1973). They are used for human consumption in certain places in the Indo-Pacific but in India they are not used as food (Kemp, 1913; Roxas \& Estampador, 1930; Tweedie, 1934; Kubo et al., 1959;

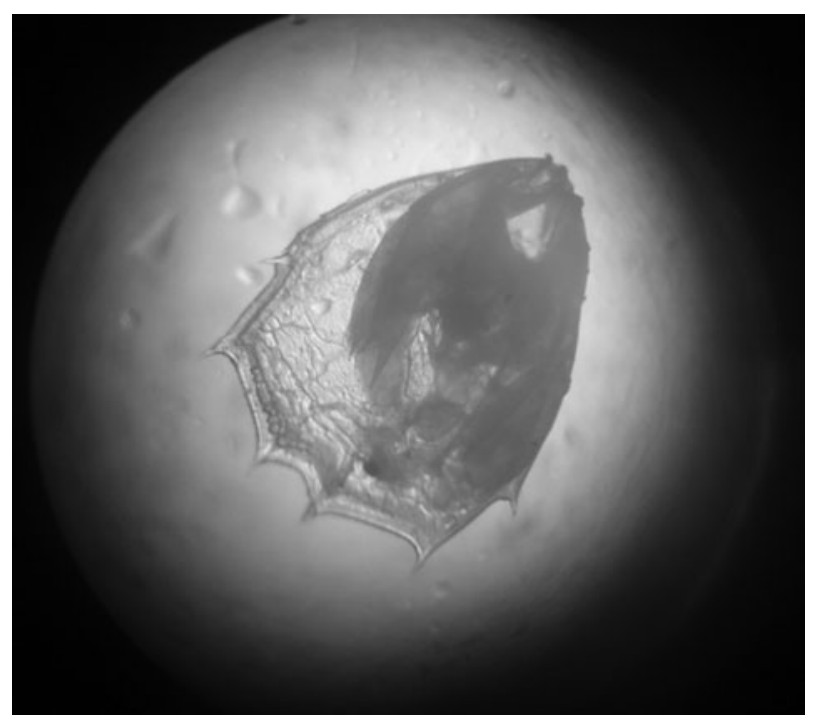

Fig. 5. Telson showing the spines and the tiny spines inbetween.

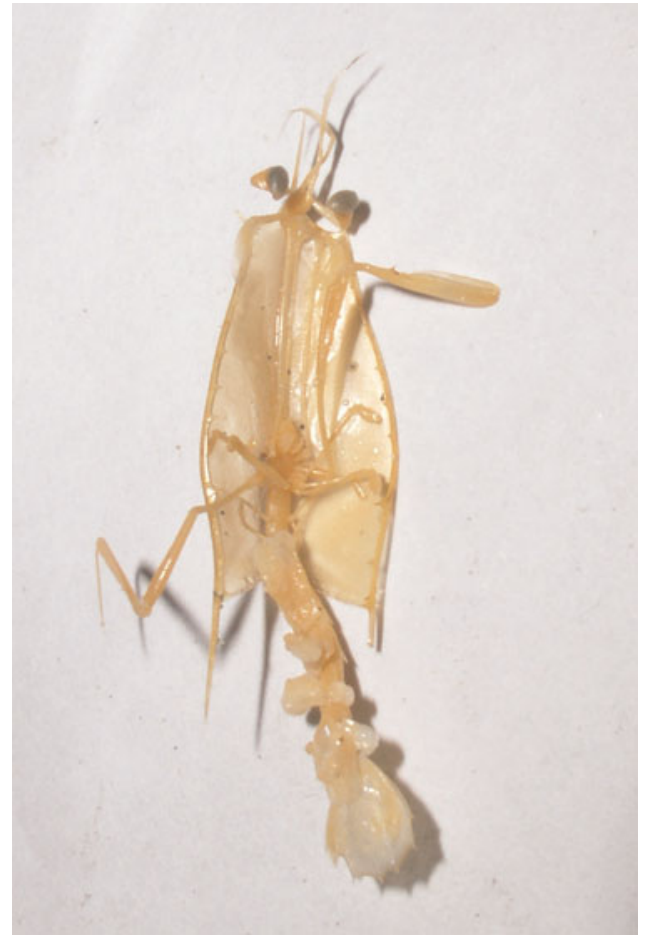

Fig. 6. Ventral view. Abdominal appendages as lumpy outgrowths.

Shanbhogue, 1973). The stomatopod exhibits two types of larval development, the earlier stages of which are passed in the burrow. Gohar \& Al-Kholy (1957) have designated the first three stages as propelagic stages and the later three stages as pelagic stages. The later stages leading to the late pelagic larval Stage 5 of stomatopod resemble the adult and prior to settling out, after six weeks or so in the plankton, they may be $5 \mathrm{~cm}$ in length and as transparent as glass. The larvae are known to be associated with coral reefs (Barber et al., 2002). Since the area under surveillance in this study has no record of coral reefs the presence of these larvae here is interesting.

Our knowledge of stomatopod larvae from the seas around India mainly stems from the extensive studies which have shown the diversity of larvae and the adults to which they belong. Taking into account the number of species known, larvae of a large number of species have not yet been identified and described. With this objective in view and for a better understanding of the distribution of stomatopod larvae from this region, detailed studies on their identification are being undertaken. The stomatopods are considered low value catch and hence discarded or used for manure and fish feed production. It is envisaged to culture these larvae in the laboratory and understand the development and to study the importance of this animal. Although mantis shrimp larvae have been reported from these waters, there has been no study that could identify them to species level until this report.

\section{ACKNDWLEDGEMENT}

The authors thank Dr Syda Rao, Director of the Central Marine Fisheries Research Institute (CMFRI) for the encouragements received. 


\section{REFERENCES}

Ahyong S.T. (2001) Revision of the Australian stomatopod Crustacea. Record of the Australian Museum 26, 1-326.

Ahyong S.T. (2002) Stomatopoda (Crustacea) from the Marquesas Islands: results of Musorstom 9. Zoosystema 24, 347-372.

Ahyong S.T., Chan T.Y. and Liao Y.C. (2008) A catalogue of the mantis shrimps (Stomatopoda) of Taiwan. National Taiwan Ocean University, Keelung I-VII, $1-190$.

Ahyong S.T. and Harling C. (2000) The phylogeny of the stomatopod Crustacea. Australian Journal of Zoology 48, 607-642.

Ahyong S.T. and Lowry J.K. (2001) Stomatopoda: Families, v. 1: 1 September 2001. http://www.crustacea.net

Alikunhi K.H. (1944a) Growth stages of Lysiosquilla tigrina Nobili. Current Science 13, 18-19.

Alikunhi K.H. (1944b) Final pelagic larva of Squilla hieroglyphica Kemp. Current Science 13, 237-238.

Alikunhi K.H. (1950) Observations on some larval and post-larval stomatopods. Journal of the Bombay Natural History Society 49, 101-107.

Alikunhi K.H. (1952) An account of the stomatopod larvae of the Madras plankton. Records of the Indian Museum 49, 239-319.

Alikunhi K.H. (1959) Notes on a collection of stomatopod larvae from the Bay of Bengal, off the Mahanadi estuary. Journal of the Zoological Society of India 10, 120-147.

Alikunhi K.H. (1965) An account of the post-larval development, moulting and growth of the common stomatopods of the Madras coast. Proceedings of the Symposium on crustacean held at Ernakulam, Marine Biological Association of India, Mandapam Camp, 12-15 January 1965, Part I. Symposia Series 2, pp. 824-938.

Alikunhi K.H. (1975) Studies on Indonesian Stomatopods. II. Notes on pelagic larvae and post-larval growth of Cloridopsis scorpio Latreille. Bulletin of the Shrimp Culture Research Centre 1, 69-78.

Alikunhi K.H. and Gopala Aiyar R. (1942) On some Squilla larvae from the Madras plankton. Current Science 11, 56-58.

Alikunhi K.H. and Gopala Aiyar R. (1943) Growth in some stomatopods. Current Science 12, 80-82.

Bano H. and Kazmi Q.B. (2007) Description of stomatopod larvae from the Arabian Sea. Pakistan Journal of Marine Sciences 16, 89-101.

Barber P.H., Palumbi S.R., Erdmann M.V. and Moosa M.K. (2002) Sharp genetic breaker among populations of Haptosquilla pulchella (stomatopoda) indicates limits of larval transport: patterns, causes and consequences. Molecular Ecology 11, 659-674.

Borradaile L.A. (1907) Stomatopoda from the western Indian Ocean. Transactions of the Linnean Society of London 12, 209-216.

Brooks W.K. (1886) Report on the Stomatopoda collected by H.M.S. Challenger during the years 1873-1876. Report of Scientific Research of H.M.S. Challenger (Zoology) 16, 1-116, pls. 1-16.

Brooks W.K. (1892) The habits and metamorphosis of Gonodadylus chiragra. Memoirs of the National Academy of Sciences 5, 353-360.

Cronin T.W., Marshall N.J., Caldwell R.L. and Pales D. (1995) Compound eyes and ocular pigments of crustacean larvae (Stomatopoda and Decapoda, Brachyura). Marine and Freshwater Behaviour and Physiology 26, 219-231.

Foxon G.E.H. (1932) Report on Stomatopod larvae, Cumacea and Cladocera. Scientific Reports. Great Barrier Reef Expedition 4, $375-398$.

Foxon G.E.H. (1939) Stomatopod larvae. Scientific Reports. John Murray Expedition 6, 251-266.
Gohar H.A.F. and Al-Kholy A.A. (1957) The larval stages of three stomatopod Crustacea. Publications of the Marine Biological Station, Al-Ghardaqa, Red Sea 9, 85-130.

Greenwood J.G. and Williams B.G. (1984) Larval and early postlarval stages in the abbreviated development of Heterosquilla tricarinata (Claus, 1871) (Crustacea, Stomatopoda). Journal of Plankton Research 6, 615-635.

Gurney R. (1937) Notes on some decapod and stomatopod Crustacea from the Red Sea, III-IV. Proceedings of the Zoological Society of London $107 \mathrm{~B}, 319-336$.

Gurney R. (1946) Notes on stomatopod larvae. Proceedings of the Zoological Society of London 116, 133-175.

Hansen H.J. (1895) Isopoden, Cumaceen, Stomatopoden der PlanktonExpedition. Ergebnisse der Plankton-Expedition der Humbolt-Stiftung, Kiel and Leipzig 2, 1-105.

Hof C.H.J. (1998) Fossil stomatopods (Crustacea: Malacostraca) and their phylogenetic impact. Journal of Natural History 32, 1567-1576.

Image Quest 3-D (2001) http://www.imagequest3d.com/pages/current/ pictureoftheweek/stomatopod/stomatopod.htm Accessed on 12/07/ 2009.

Jutte P.A., Cronin T.W. and Caldwell R.L. (1998) Photoreception in the planktonic larvae of two species of Pullosquilla, a Lysiosquilloid stomatopod crustacean. Journal of Experimental Biology 201, 2481-2487.

Ingle R.W. and Della Croce N. (1967) Stomatopod larvae from the Mozambique Channel. Bollettino dei Musei e degli Instituti Biologici della Universitá di Genova 35, 55-70, figs. 1-25.

Kemp S. (1913) An account of the Crustacea Stomatopoda of the Indo-Pacific region based on the collection in the Indian Museum. Memoirs of the Indian Museum 4, 1-217, 10 text-figs., pls. 1-10.

Kubo I., Hori S., Kumemura M., Naganawa M. and Soedjono J. (1959) A biological study on a Japanese edible, mantis-shrimp Squilla oratorio de Haan. Journal of the Tokyo University of Fisheries 45, 1-25, textfigs. $1-16$.

Lanchester W.F. (1903) Marine crustaceans. VIII. Stomatopoda, with an account of the varieties of Gonodactylus chiragra. In Gardiner J.S. (ed.) The fauna and geography of the Maldive and Laccadive Archipelagoes, being the account of the work carried out and of the collections made by an expedition during the years 1899 and 1900 5, 444-459.

Lebour M.V. (1954) The plankton Decapod Crustacea and Stomatopoda of the Benguela Current. Part I. First survey, R.R.S. 'William Scoresby' March 1950, Discovery Report 27, 219-234.

Lele S.H. (1937) Pelagic larva of Squilla interrupta. Proceedings of the 24th Indian Scientific Congress, Hyderabad.

Manning R.B. (1962) Alima hyalina Leach, the pelagic larva of the stomatopod crustacean Squilla alba Bigelow. Bulletin of Marine Science of the Gulf and Caribbean 12, 496-507.

Manning R.B. (1991) Stomatopod Crustacea collected by the Galathea Expedition, 1950-1952, with a list of Stomatopoda known from depths below 400 meters. Smithsonian Contributions to Zoology 521, $1-18$.

Manning R.B. (1995) Stomatopod Crustacea of Vietnam: the legacy of Raoul Serène. The Carcinological Society of Japan. Crustacean Research, Special Issue No. 4, 1-339.

Manning R.B. and Provenzano Jr A.J. (1963) Early developmental stages of the stomatopod crustacean Gonodactylus oerstedii Hansen. Studies on the development of stomatopod Crustacea, 1. Bulletin of Marine Science of the Gulf and Caribbean 13, 467-487.

Michel A. and Wing R.B. (1972) The pelagic larvae of Chorisquilla tuberculata (Borradaile, 1907) (Stomatopoda). Crustaceana 22, 113-126. 
Milne-Edwards H. (1837) Historie naturelle des crustacés, comprenant I'anatomie, la physiologie et la classification de ces animaux 2, 1-532.

Moazzam N. and Moazzam M. (2006) Stomatopod larvae from Pakistan coast-I. Taxonomic enumeration. Pakistan Journal of Zoology 38, $177-184$.

Morgan S.G. and Provenzano Jr A.J. (1979) Development of pelagic larvae and postlarva of Squilla empusa (Crustacea, Stomatopoda) with an assessment of larval characters within the Squillidae. Fishery Bulletin. Fish and Wildlife Service. Washington, DC 77, 61-90.

Nair K.B. (1941) On the embryology of Squilla. Proceedings of the Indian Academy of Sciences, Series B 14, 543-576, figs. 1-31, pls. 29-30.

Provenzano A.J. and Manning R.B. (1978) Studies on development of stomatopod Crustacea. II. The later larval stages of Gonodactylus oerstedii Hansen reared in the laboratory. Bulletin of Marine Science 28, $297-315$.

Roxas H.A. and Estampador E. (1930) Stomatopoda of the Philippines. National Applied Science, Manila 1, 93-131, pls. 1-6.

Serene R. (1954) Observations biologiques sur les stomatopods. Memoirs of the Institute of Oceanography, Nhatrang 8, 1-93.

Shanbhogue S.L. (1969) Catalogue of stomatopods in the reference collections of the Central Marine Fisheries Research Institute. Bulletin of the Central Marine Fisheries Research Institute 9, 35-36.

Shanbhogue S.L. (1973) Stomatopods as a potential resource. Proceedings of the symposium on living resources of the seas around India. Special Publication of the Central Marine Fisheries Research Institute, 592595.

Shanbhogue S.L. (1975a) Descriptions of stomatopod larvae from the Arabian Sea with a list of stomatopod larvae and adults from the
Indian Ocean and a key for their identification. Part I. Journal of the Marine Biological Association of India 17, 196-238.

Shanbhogue S.L. (1975b) Descriptions of stomatopod larvae from the Arabian Sea with a list of stomatopod larvae and adults from the Indian Ocean and a key for their identification. Part 2. Journal of the Marine Biological Association of India 17, 522-544.

Shanbhogue S.L. (1978) The embryonic and early larval development of Gonodactylus falcatus (Forsskål) (Crustacea: Stomatopoda) from India. Journal of the Marine Biological Association of India 20, 86-97.

Tattersall W.M. (1906) Report on the Leptostraca, Schizopoda, and Stomatopoda collected by Professor Herdman, at Ceylon, in 1902. Herdman, Report to the Government of Ceylon on the Pearl Oyster Fisheries of the Gulf of Manaar 5, 157-188, pls. 1-3.

Townsley S.J. (1953) Adult and larval stomatopod crustaceans occurring in Hawaiian waters. Pacific Science 7, 399-437, figs. 1-28.

and

Tweedie M.W.F. (1934) Notes on Stomatopoda in the Raffles Museum. Bulletin of the Raffles Museum 9, 33-41, pl. 1.

\section{Correspondence should be addressed to:}

S. Veena

Visakhapatnam Regional Centre of CMFRI

Pandurangapuram

Visakhapatnam 530003

India

email: veenashettigar@yahoo.co.in 